\title{
ANÁLISE ERGONÔMICA DO SETOR DE ALMOXARIFADO DE HOSPITAL PÚBLICO DE LONDRINA-PR
}

Ergonomic analysis of industry warehouse of public hospital Londrina - Pr

\author{
AIEX, Viviane Mantovani I Mestre em Eng. Produção \\ Universidade Norte do Paraná - UNOPAR \\ vivianeaiex@hotmail.com
}

\section{CAVALIERI, Nathalia I Graduanda em Desenho Industrial}

Universidade Norte do Paraná - UNOPAR

cavalieri.nath@outlook.com

\section{ZARANTONELLO, Letícia I Graduanda em Desenho Industrial}

Universidade Norte do Paraná - UNOPAR

let_zarantonello@hotmail.com

\begin{abstract}
Resumo
O presente trabalho apresenta estudo de caso sobre ergonomia em um setor de almoxarife de um hospital público da cidade de Londrina, Paraná. Foi realizado um questionário qualitativo e levantamento de dados no modo fotográfico e revisão literatura. Detectaram-se erros ergonômicos e estruturais no estabelecimento, e pode se verificar que não há aplicação das Normas ABNT e muito menos cuidados referentes à preservação e modificações do Abstract

This paper presents a case study on ergonomics in a sector storekeeper of a public hospital in the city of Londrina, Paraná. A qualitative questionnaire and data collection was carried out in photo mode and review the literature. Were detected ergonomic and structural errors in the establishment, and it was observed that there is no implementation of ABNT much less regarding the preservation and care of the environment changes.
\end{abstract} ambiente.

Palavras-Chave: Hospital público. Ergonomia.

Keywords: Public hospital. Ergonomic. Warehouseman.

Almoxarife. 


\section{INTRODUC̣ÃO}

Muitas vezes o espaço em que o almoxarife se encontra nem sempre é o necessário para comportar a quantidade de equipamentos, utensílios e tudo o que um hospital necessita no seu dia a dia, esse espaço ainda precisa ser um ambiente que suporte as necessidades que os trabalhadores precisam.

Em geral, o setor de almoxarife necessita de um projeto para adequar o espaço da melhor forma possível, propiciando que o trabalho no local seja feito de forma adequada pelos funcionários, esses projetos necessitam de aprovação do Estado e que o mesmo libere os recursos necessários para a realização do projeto.

As instalações internas utilizadas para estocagem dos materiais encontram-se obsoletas, improdutivas, ineficientes e anti-ergonômicas, sendo necessário um estudo de layout, investimentos em prateleiras modulares, para maior controle dos materiais estocados e maior eficiência dos serviços prestados.

Visto que as instalações do almoxarifado decorrem de adequações de áreas já existentes, projetadas para outros fins, tanto os pisos quanto os pésdireitos não estão adequados às necessidades requeridas para as operações de recebimento, estocagem e distribuição de materiais.

O objetivo geral deste projeto é analisar o layout do ambiente de trabalho, verificando os aspectos ergonômicos aplicados.

Os objetivos específicos se encontram em fazer um levantamento de dados, para poder visualizar e propor melhorias no almoxarifado, aumentar a produtividade, eficiência e adequar à ergonomia.

A ergonomia tem como objetivo fornecer diretrizes de trabalho, eficiência, aperfeiçoamento no sistema de controle, armazenamento e distribuição de materiais, para o melhoramento das condições, permitindo maior conforto operatório e segurança, integrando critérios de produtividade e qualidade.

Ointeressante da disciplina de Ergonomia estána reunião de conhecimentos que compõem a partir de diversas áreas diferentes, como fisiologia, psicologia, engenharia, entre outras, refletindo na capacidade do ser humano de fortalecer sua adaptação ao meio-ambiente, no seu campo de trabalho, através da criação de produtos e ambientes mais confortáveis, práticos e funcionais.

O benefício das mudanças pode ser visto na facilidade e praticidade de 
manuseio dos produtos, assim como maior satisfação por parte dos funcionários e pessoas que frequentam o ambiente modificado.

\section{DESENVOLVIMENTO}

\section{Ergonomia}

Associação Brasileira de Ergonomia - ABERGO, define ergonomia como a ciência das interações do homem com a tecnologia, a organização e o ambiente com o propósito de melhorar projetos e de forma não dissociada e integrada a segurança, o conforto e bem-estar das atividades do homem (ABERGO, 2008).

Ilda (1990), relata que para um projeto do trabalho humano, há três aspectos que devem ser considerados: monotonia; fadiga; motivação. Depois devem ser considerados a esses aspectos a idade, sexo e deficiências físicas.

A ergonomia preocupa-se com partes fisiológicas do posto de trabalho envolvidos, segundo Chambers, Johnston e Slack (1997), ou seja, como o corpo humano se comporta no ambiente, sendo importante indicar o comportamento das pessoas sob diferentes condições de trabalho, tentando encontrar o melhor conjunto de condições de conforto e desempenho para a realização do mesmo.

De acordo com Ilda (1990), a Análise Ergonômica do Trabalho - AET tem como objetivo aplicar os conhecimentos da ergonomia para analisar, diagnosticar e corrigir uma condição de trabalho. Ela foi desenvolvida por pesquisadores franceses e é considerada um exemplo de ergonomia de correção.

Para Chaffin, Anderson e Martin (2001), os programas de análise ergonômica contemporânea do trabalho, considerando as questões de biomecânica, têm três elementos principais: a identificação da prevalência e do tipo de problema músculo-equelético, a análise dos fatores do trabalho que expõem o indivíduo ao risco de problema músculo-esqueléticos específicos e a avaliação para determinar o grau de risco em determinadas populações de trabalhadores.

Durante a jornada de trabalho, um trabalhador pode assumir centenas de posturas diferentes, o que tornou a sua identificação e registro uma das maiores dificuldades em se analisar e corrigi-las (IIDA, 1990).

Uma área de trabalho que frequentemente apresenta problemas relacionados à ergonomia é, sem dúvida, a área do almoxarifado de materiais e acessórios, devido ao fato de alguns trabalhadores deste posto estarem afastados ou já vem apresentando problemas relacionados a lombalgias. 
Por isso, fica claro que é necessária uma análise mais minuciosa do fato. Tendo em vista a utilização de pessoas para a execução de trabalhos considerados pesados, a análise ergonômica do posto de trabalho é de grande importância, pois poderá identificar problemas não verificados por uma análise mais simplificada destes tipos de trabalho.

\section{Antropometria}

No decorrer da evolução do corpo humano das pessoas, estas sofrem mudanças de forma e proporções. Essas mudanças podem ser mais visíveis durante seu crescimento na infância e na adolescência. Já o processo de envelhecimento inicia-se após os 30 anos.

Em geral, os homens são mais altos do que as mulheres, e também possuem maior força. Para Ilda (1990), isso se reflete também no campo de trabalho. Pois, trabalhar num almoxarifado, com estrutura de mais de um andar, aonde trabalham homens e mulheres de diferentes estaturas e idades, pode sim contribuir para problemas como dores nas costas, acidentes, entre outros.

De acordo com Grandjean (1998) a Norma 17, relata os itens pertinentes para o trabalho. Descreve como deve ser feito o transporte, estoque e levantamento de materiais, quais posturas deve ter o trabalhador, como proporcionar segurança e conforto para o usuário, no seu campo de trabalho.

Porém, nem sempre é fácil melhorar ou adequar um ambiente, visto que pessoas de diferentes estaturas, pesos, idades e sexos diferentes participam do mesmo lugar. Porém, cabe ao empregador fazer esta análise.

A área de trabalho deve propiciar fácil alcance aos trabalhadores, visibilidade, facilidade de manuseio dos equipamentos, materiais, entre outros itens que façam parte do cotidiano deste empregado. Deve ter características dimensionais que possibilitem o posicionamento e movimentação adequados do corpo.

Em geral, as mulheres são mais baixas, cerca de $12 \mathrm{~cm}$ em relação aos homens, trabalham em ambientes projetados para os homens, o resultado é que a adaptação aos equipamentos é fatigante.

Para Tilley e Dreyfuss (2005), existirão mais pessoas na faixa dos 40 e 50 anos no mercado de trabalho, a aplicação de ergonomia ao projeto dos objetos e ambientes requer um conhecimento melhor dessas pessoas. 
Nos dados antropométricos é visível as mudanças em relação ao alcance e flexibilidade, principalmente dos braços. Porém, o tronco e pernas também sofrem modificações, o que vem impactar num determinado tipo de trabalho, como por exemplo, a pessoa precisar subir e descer escadas, carregar pesos constantemente, entre outros.

As mulheres aos 50 anos possuem a metade da força do homem com a mesma idade, há um declínio uniforme em todas as partes do corpo. Os braços e mãos são menos afetados já o tronco e pernas são os mais prejudicados. Isso pode facilitar um tombo dentro do almoxarifado, fazer com que o equilíbrio seja prejudicado, pois há excesso de materiais. Então subir as escadas, permanecer no mezanino para colocar ou pegar materiais, pode ser um facilitador para acidentes.

Afinal os reflexos tornam-se mais lentos, diminui a força, e essas diferenças tendem a crescer em tarefas mais complexas, que exijam mais atenção. Como no almoxarifado trabalham pessoas de idades e sexos diferentes, tem poder de influenciar sim, negativamente, sobre a qualidade de trabalho neste ambiente.

\section{MATERIAIS E MÉTODOS}

A partir de um Estudo de Caso, foi investigado e explorado um almoxarife, na intenção de ver a fundo os problemas ergonômicos. Além do estudo de campo, foi feita uma entrevista com as pessoas que trabalham no almoxarifado, através de um questionário com perguntas abertas.

Para reforçar a problemática, somente entrevistar os funcionários do almoxarife não foi suficiente para concretização e confirmação dos dados levantados, sendo assim, se fez necessário obter imagens que registrassem os acontecimentos referentes às reclamações. Pode ser visto então nas Figuras de 1 a 7 , alguns problemas citados anteriormente. 
Figura 01 - Corredor feito por caixas empilhadas tampando as janelas e entrada de ar e luz.

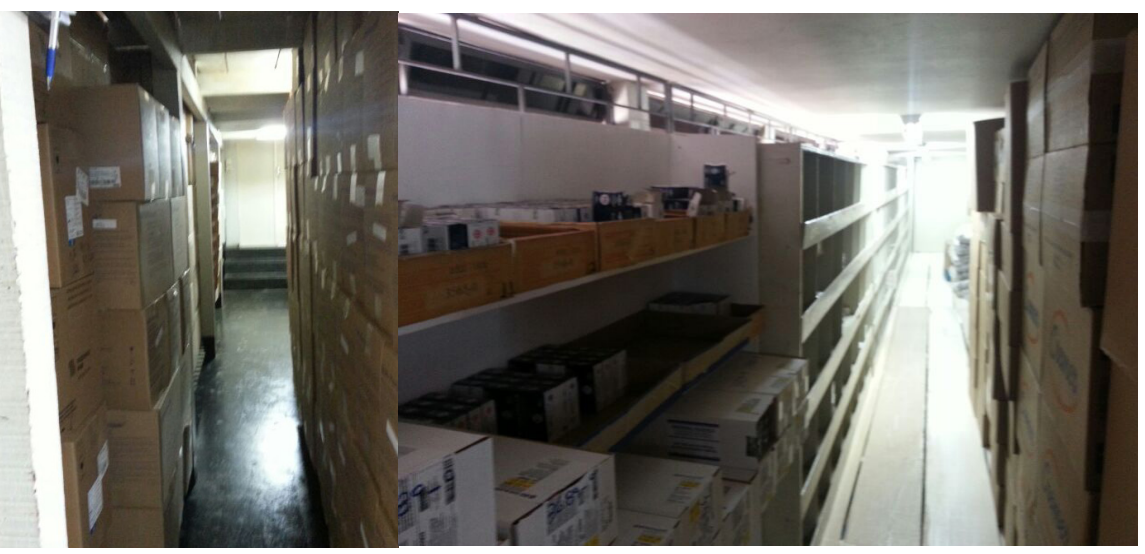

Fonte: Arquivo próprio.

Figura 02 - Prateleiras empilhadas e escada de madeira não fixa, para alcance dos produtos.

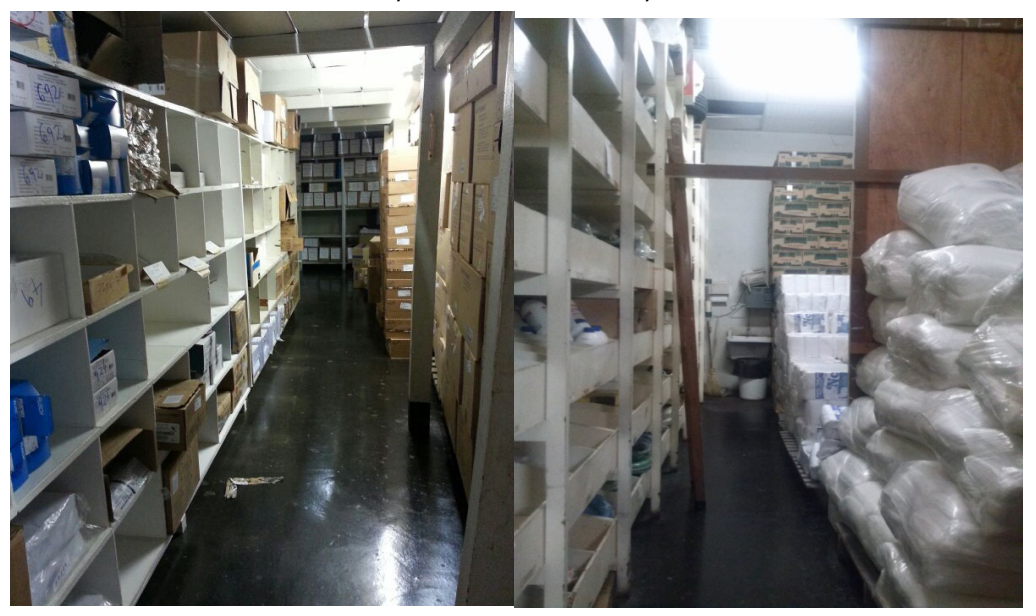

Fonte: Arquivo próprio.

Figura 03 - Andar sem parapeito, muitas caixas empilhadas, perigo de acidente.

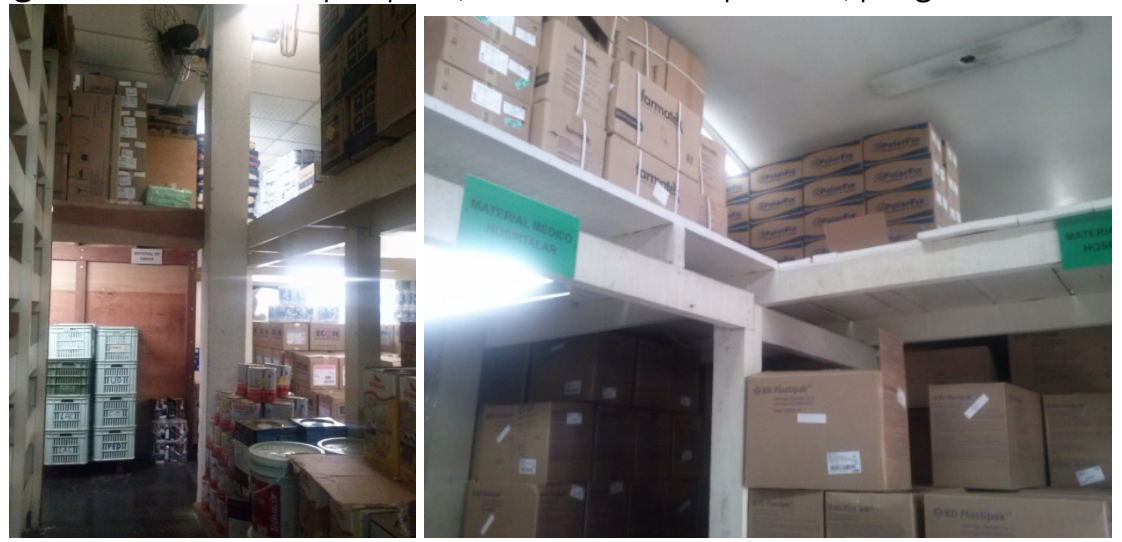

Fonte: Arquivo próprio. 
Figura 04 - Chão feito com tábuas de madeira pregadas a uma armação, sem proteção nenhuma.

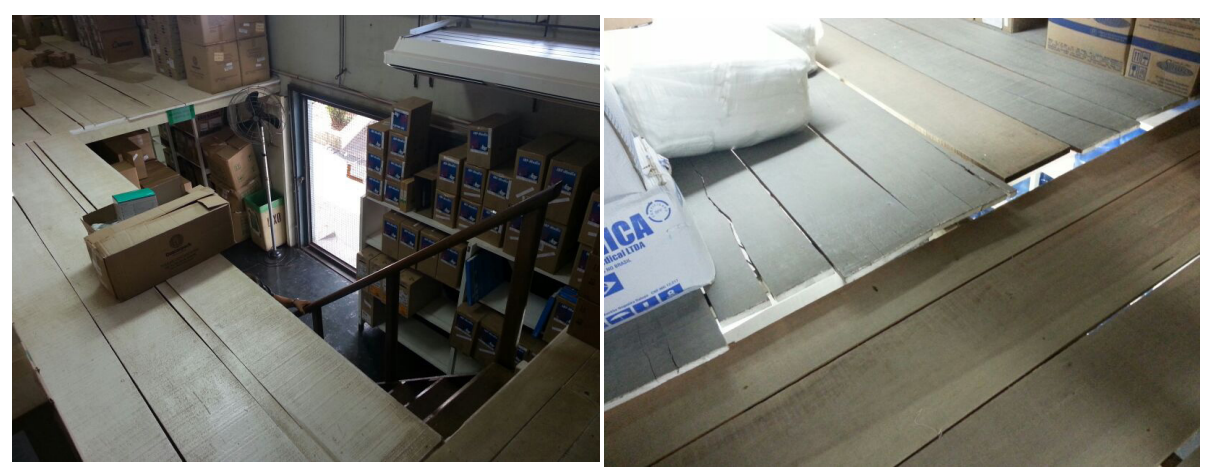

Fonte: Arquivo próprio.

Figura 05 - Escada fixa sem corrimão, muito íngreme, degraus muito curtos e juntos.

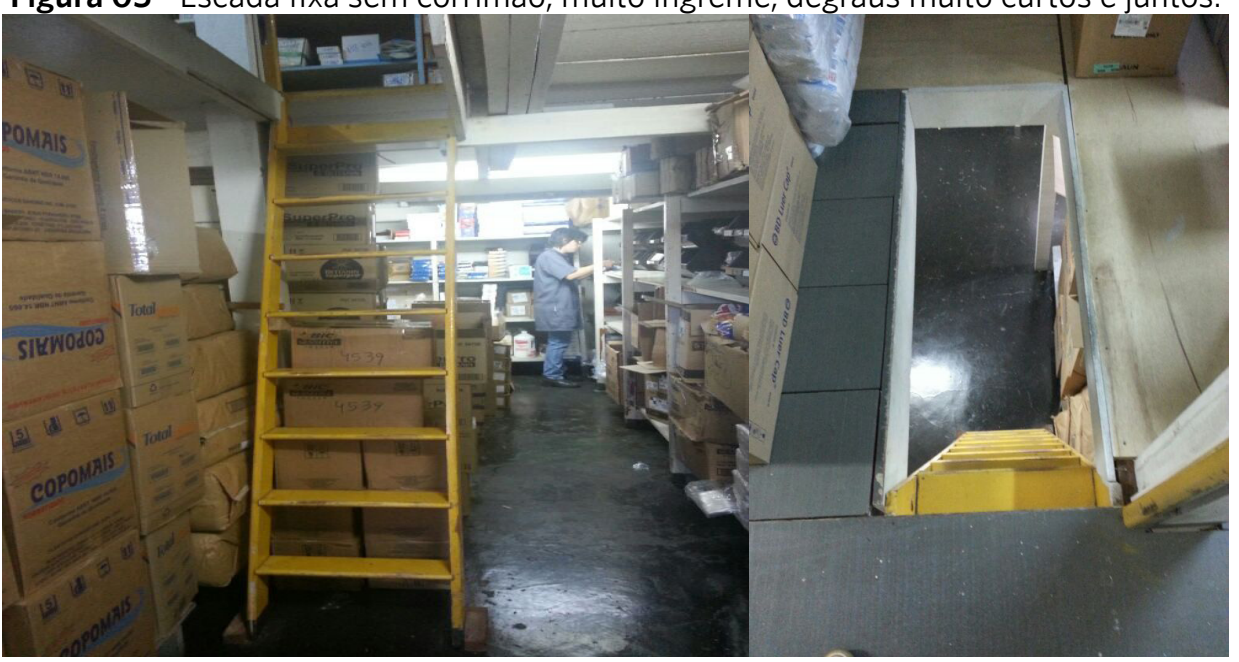

Fonte: Arquivo próprio.

Figura 06 - Área de produtos vencidos e carrinho transporte de cargas.

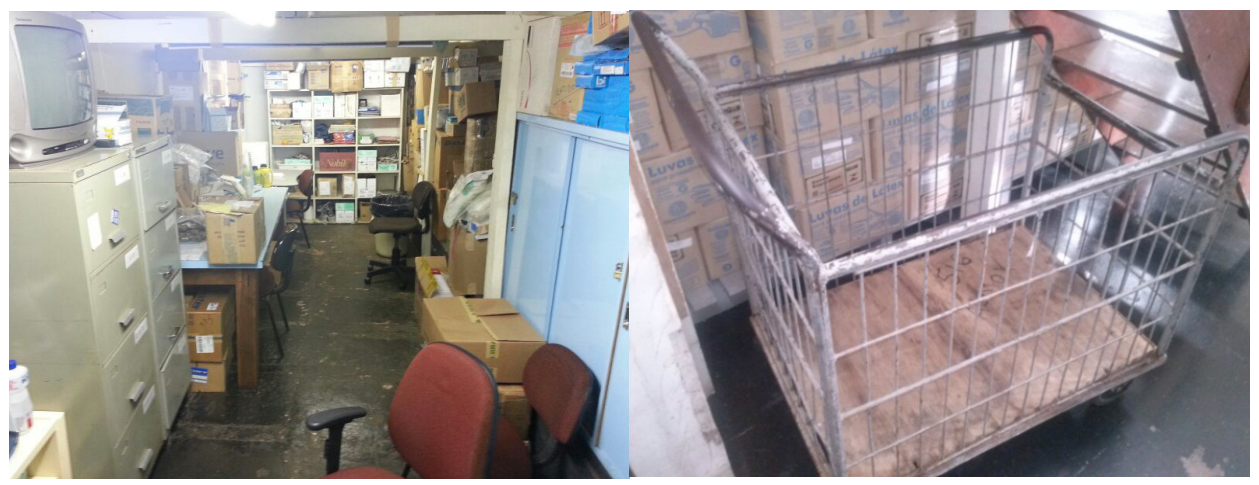

Fonte: Arquivo próprio. 
Figura 07 - Andar sem segurança alguma, ventilador exposto e escada não fixa, sem corrimão.

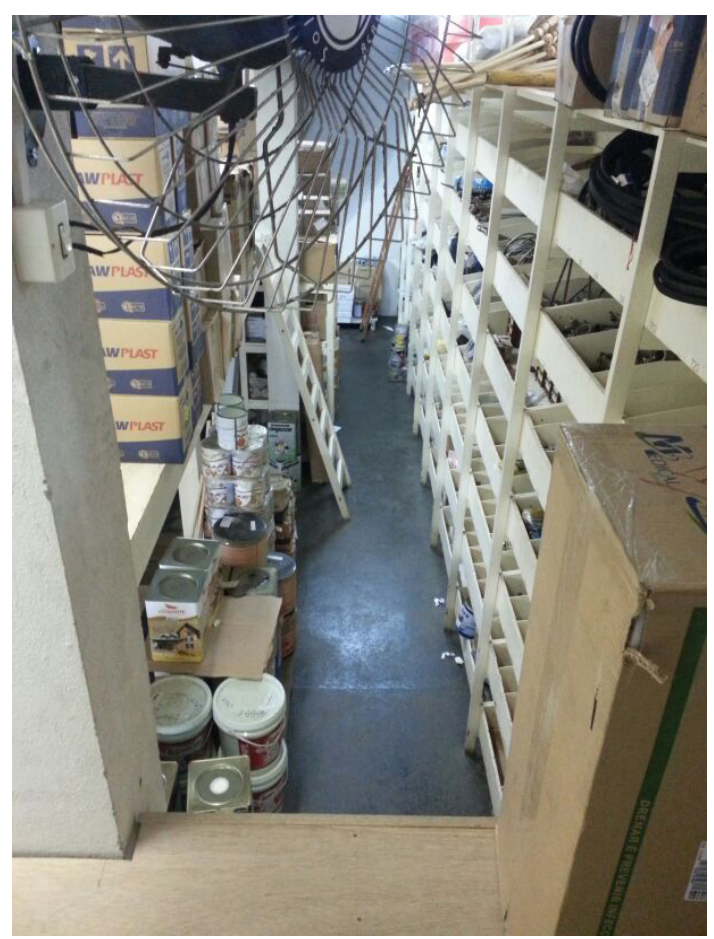

Fonte: Arquivo próprio.

Além das imagens foram perguntadas as seguintes questões:

1- O espaço do almoxarifado é suficiente para execução das tarefas?

2- Os arquivos são de fácil alcance?

3- O mobiliário, equipamentos e ferramentas são eficientes e seguros?

4- As condições de trabalho são boas? (iluminação, temperatura, ruídos, vibrações, qualidade do ar, cor do ambiente)

5- Quais os problemas encontrados neste espaço?

6- O trabalho realizado aqui causa algum desconforto ou dores?

7- A "empresa" oferece algum tipo de atividade durante o intervalo do trabalho? (ginástica laboral ou atividade para aliviar o estresse)

8- Conhece alguém que sofreu algum tipo de acidente?

9- Encontrou algum inseto ou algum animal?

As questões foram de grande valia para detectar as insatisfações por parte dos funcionários, referentes às dificuldades de andar no local, de realizar transporte e manuseio dos produtos estocados.

Além disso, percebeu-se que muitos empregados possuem idade acima de 50 anos, o que pode contribuir para aumento de dificuldades em pegar um produto, transportá-lo, na diminuição da força para pegá-lo, na memorização e visualização dos mesmos. 
De acordo com Tilley e Dreyfuss (2005) e Ilda (1990), nos velhos a acuidade visual se deteriora como resultado do processo de envelhecimento. Com a idade os olhos levam mais tempo para fazer o foco e perceber as cores, devido ao amarelamento do cristalino. O resultado: fica mais difícil distinguir cores como o verde, azul e violeta.

Ou seja, o tempo de reação dos olhos duplica com o envelhecimento, o ofuscamento duplica com a velhice. Uma pessoa com mais de 40 anos de idade necessita do dobro do nível de iluminação do que outra de 20 anos. Uma pessoa com mais de 60 anos precisa de cinco ou seis vezes mais luz do que uma pessoa com 20 anos de idade.

\section{RESULTADOS}

De acordo com o questionário aplicado nos servidores do almoxarifado, foi constatado que o espaço do mesmo não é suficiente para execução das tarefas, os arquivos mesmo de fácil alcance não são eficientes, o mobiliário (equipamentos e ferramentas) não são adequados e seguros, e as condições de trabalho oferecem somente o mínimo de conforto para os servidores.

A empresa hoje não oferece mais atividade durante intervalo, pois antes eram feitas por alunos que atuavam como estagiários, encaminhados pela universidade vinculada a instituição. Mesmo tendo pouco espaço e condições precárias em alguns aspectos como ergonomia, não foram relatados acidentes na entrevista.

Já na questão da limpeza do local, apesar de vários produtos estarem armazenados em caixas de papelão, não foram encontrados nem relatados qualquer tipo de insetos ou animais, pois o local é constantemente limpo.

De acordo com a visita, entrevistas e questionários foi percebido que muitas coisas precisam ser modificadas, para melhor funcionalidade e ergonomia do local. O hospital cresceu muito rápido e as instalações não acompanharam a demanda.

Precisaria de um local muito maior que o disponível, instalações e equipamentos mais seguros, como escadas fixas com corrimão, parapeito, uma estrutura correta para armazenamento e convívio, pois o local em questão é feito de "improvisos necessários" por falta de estrutura.

A seguir, observa-se na Tabela 1, a descrição dos principais problemas detectados no ambiente. Isso ajuda a proporcionar indagações e propostas de 
soluções.

Quadro 01 - Descrição dos principais problemas detectados no ambiente.

\begin{tabular}{|c|c|c|c|}
\hline $\begin{array}{l}\text { ASPECTOS REFERENTES AOS } \\
\text { REQUISITOS MÍNIMOS EXIGI- } \\
\text { DOS NO AMBIENTE PESQUISA- } \\
\text { DO }\end{array}$ & ATENDE & $\begin{array}{l}\text { NÃO } \\
\text { ATENDE }\end{array}$ & $\begin{array}{c}\text { ATENDE } \\
\text { PARCIAL- } \\
\text { MENTE }\end{array}$ \\
\hline Ergonomia & & & \\
\hline Espaço de uso & & $x$ & \\
\hline Armazenamento & & $x$ & \\
\hline Ambiente & & & $x$ \\
\hline Manuseio dos produtos & & & $x$ \\
\hline Escadarias & & $\mathrm{x}$ & \\
\hline Equipamentos para transporte & & & $x$ \\
\hline Espaço para fluxo de funcionários & & $\mathrm{x}$ & \\
\hline Prateleiras com divisórias & & $x$ & \\
\hline Equipamentos para segurança & & & $x$ \\
\hline $\begin{array}{l}\text { Equipamentos para controle de } \\
\text { temperatura }\end{array}$ & & & $x$ \\
\hline Boa visibilidade & & & \\
\hline
\end{tabular}

Fonte: Arquivo próprio.

Viu-se que muitos itens deixam a desejar e que se seguissem regras e normas ergonômicas poderiam obter resultados mais satisfatórios. É visível a constatação das problemáticas apontadas.

\section{CONCLUSÕES}

Para tanto, conclui-se que as instalações, equipamentos e espaço, não atendem em quesitos ergonômicos para as atividades e necessidades de um almoxarife. Precisaria de um grande investimento e tempo da instituição para essas reformas. 
Tendo isso, as condições de serviço, atendimento e trabalho melhorariam, tornando mais eficiente o funcionamento do hospital e almoxarife, assim otimizando o fácil acesso aos produtos e proporcionando o armazenamento correto no estoque, em questões ergonômicas.

Sendo assim, fica visível que modificações devem acontecer no almoxarifado, pois não está atendendo as necessidades mínimas para o trabalho. Não há iluminação e nem ventilação adequadas, as caixas de papelão tampam as janelas, atrapalham a locomoção das pessoas.

Um estabelecimento deve favorecer a locomoção dentro dele, influenciar na facilidade de visualização, memorização dos produtos, na praticidade de se colocar e retirar os mesmos das prateleiras, adotar procedimentos seguros para não ocorrer acidentes e reduzir as incertezas.

\section{REFERÊNCIAS}

ASSOCIAÇÃO BRASILEIRA DE ERGONOMIA - ABERGO. O que é ergonomia. 2008. Disponível em: <http://www.abergo.org.br/internas. php?pg=o_que_e_ergonomia>. Acesso em: 28 maio 2014.

CHAFFIN, D. B.; ANDERSON, G. B. J.; MARTIN, B. J. Biomecânica ocupacional. Belo Horizonte: Ergo, 2001.

CHAMBERS, S.; JOHNSTON, R.; SLACK, N. Administração da produção operations management. São Paulo: Atlas, 1997.

GRANDJEAN, E. Manual de ergonomia: adaptando o trabalho ao homem. 4. ed. Porto Alegre: Bookman, 1998.

IIDA, I. Ergonomia: projeto e produção. São Paulo: Edgard Blücher, 1990.

TILLEY, A. R.; DREYFUSS, H. As medidas do homem e da mulher - fatores humanos em design. São Paulo: Bookman, 2005. 104 p. 


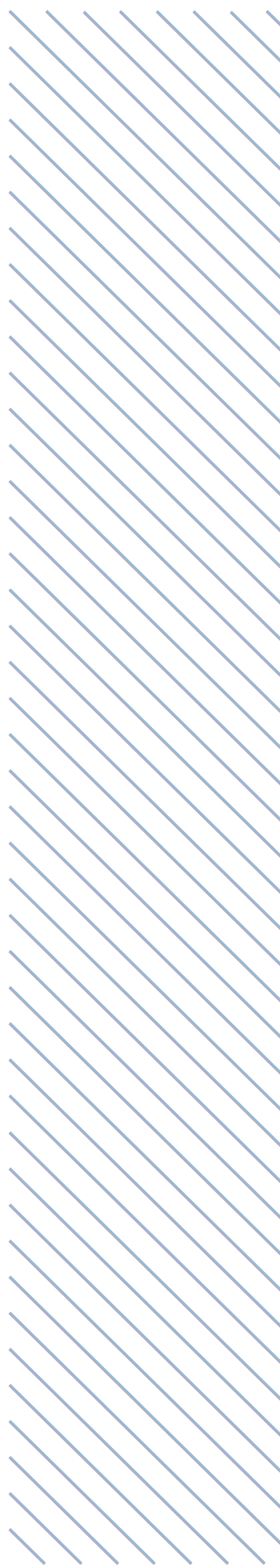

